\title{
歯牙切削時における歯髄腔内の温度変化
}

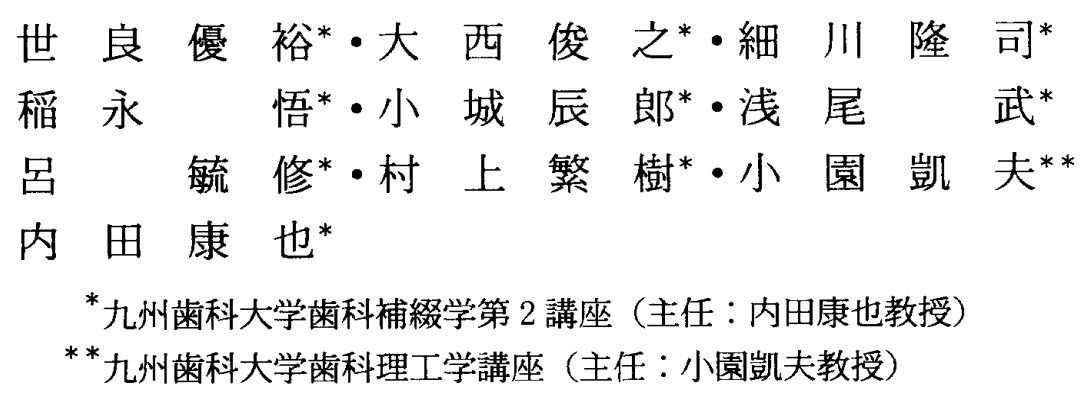

平成 4 年 2 月 26 日受理

\section{Temperature Change in Pulp Chamber during Tooth Cutting}

\author{
Masahiro Sera*, Toshiyuki Ohnishi*, Ryuji Hosokawa*, Satoru Inanaga*, \\ Taturo Kojo*, Takeshi Asao*, Yuh-Shiou Lu*, Shigeki Murakami*, \\ Yoshio Kozono** and Yasunari Uchida* \\ ${ }^{*}$ Second Department of Prosthetic Dentistry (Chief : Prof. Yasunari Uchida) \\ ${ }^{* *}$ Department of Materials Science (Chief : Prof. Yoshio Kozono) \\ Kyushu Dental College, Kitakyushu, Japan
}

In tooth preparation, the heat generation by cutting may cause injury to the pulp as well as severe discomfort to the patient.

In this study, in vitro measurements of the temperature changes in the pulp chamber during cutting were performed on extracted human incisors. The tooth was cut inward from its labial surface with an air-turbine handpiece under each combination of the conditions of

(1) cutting load: 20,50 and $80 \mathrm{~g}$; (2) grit size of diamond bur : coarse, regular and fine; and ( 3 ) water spray : 0,1 and $5 \mathrm{ml} / \mathrm{min}$.

When the cutting load was small, the temperature rise of the pulp chamber was small and the temperature rather decreased by water spray. As the cutting load increased, the temperature of the pulp chamber increased; however, the increment varied according to the interaction of the load and the amount of water. No significant differences were found in the temperature change between the coarse and regular grit sizes of the diamond bur used, while the temperature rise was minimum with the grit size of the bur.

Key words : Tooth cutting/Temperature change/Cutting load/Grit size/Water spray

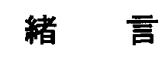

生活歯の切削は, 高速切削器具の進歩および切削時の
疼痛軽減を目的とした局所麻酔の採用などによって, 容 易かつ正確に，しかも短時間で行えるようになってき た.しかし，高速切削により発熱，振動，象牙細管およ 
び象牙線維の機械的損傷，象牙細管内ならびに歯䯣腔内 の圧力変化などの複合的な刺激が生じ，歯䯣に可逆的あ るいは非可逆的な反応を引き起こすことが数多く報告さ れている1-4).

そこで, 生活歯に窩洞形成や支台歯形成を行う場合, よ゙の様な条件で切削を行えば，歯䯣に対して最も為害作 用を与えないのかが重要な問題となる。このため, 注水 量および方法, 回転数, 切削器具の種類ならびに形態, 切削量などについて多くの検討がなされてきだ

本研究では, 切削圧, ダイヤモンドバーの粒子の粗 さ, 切削時の注水量の 3 つの条件を設定し，それぞれの 条件が歯牙切削時において雨髄腔内の温度变化におよぼ す影響について実験を行った。

\section{実験材料と方法}

本実験に用いた材料, 切削装置, 切削方法, 温度測定 方法は以下の通りである.

\section{I . 材料}

本実験には，充買物やカリエスなよ゙がない解剖学的に 正常な形態を有するヒト下颏切歯抜去霜牙で, 生理食塩 水中に浸漬, 保存したものを使用した. 歯牙表面に付着 した䨑根膜, 歯石などをスケーラーを用いて除去した 後, 根尖から $1 \mathrm{~mm}$ の部位をダイヤモンドディスクで切断 し, その切断面加ら歯冠方向へ 1 番のピーソーリーマー で根管を拡大した.

II. 切削装置

歯牙の切削には，歯科研削シュミレーション装置（モ リ夕製作所）を用いた。この装置には回転数検出セン サーおよび振動検出センサーが組み込まれたエアベアリ ングハンドピース（アストロン，モリ夕）が装備されて

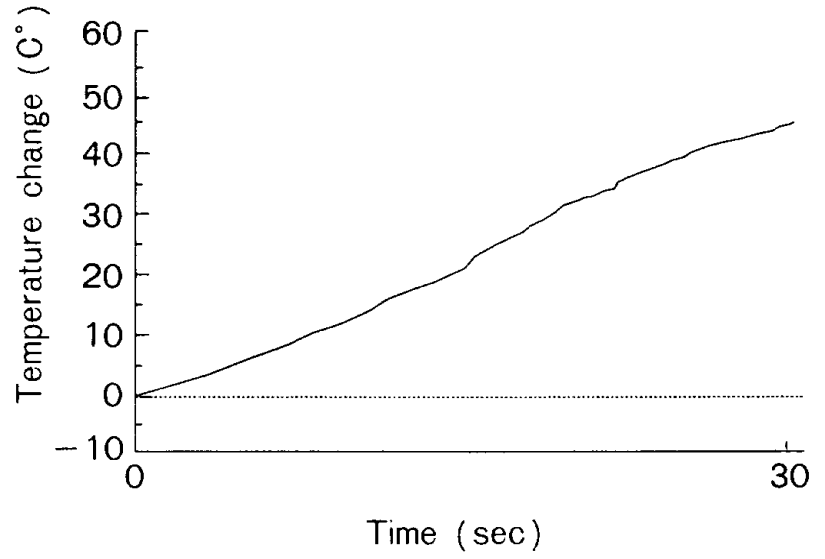

Fig. 1 An example of temperature rise in pulp chamber during cutting.
いる. また，歯牙の固定チャックには X $\mathrm{Y} \cdot \mathrm{Z}$ 三軸セ ンサーが連結され，三方向の切削荷重が測定できる.

III. 切削方法

切削は以下に示す条件をそれぞれ組み合わせた計 27 通りの条件下で，各 5 本ずつ，計 135 本の歯牙に対して 行った，切削は，シュミレーション装置上の歯牙固定 チャックに装着した歯牙の唇面中央部を唇面から歯䯣腔 に向けて行った．切削開始時，バーは歯軸と平行となる ようにし, バーの先端は歯牙の解剖学的歯頸線と一致さ せた。 また，ハンドピースの把持部は䨑軸に対して垂直 とした，歯牙を切削する時間はいずれの条件においても 30 秒とした.

A. 切削圧 : $20,50,80 \mathrm{~g}$

B、ダイヤモンドバーの粒子の粗さ：コース，レギュ ラー, ファイン（ダイヤモンドインスッルメンッ FG, Bur NO. $102 \mathrm{R}$, 松風)

C. 切削時の注水量： $0 \mathrm{ml} / \mathrm{min}, 1 \mathrm{ml} / \mathrm{min}, 5 \mathrm{ml} /$ $\min$

IV. 温度測定方法

歯䯣腔内の温度変化の測定には，温度測定用センサー （直径 $0.5 \mathrm{~mm}$, 安立計器）を用いた。根尖側から挿入し たセンサーによって得られた歯牙切削時の歯䯣腔内の温 度変化を,レコーダー（R-02, 理科電気工業）にて記 録した。なお，実験中の室温は $25 \pm 1{ }^{\circ} \mathrm{C}$ ，水温は 18 $\pm 1{ }^{\circ} \mathrm{C}$ に保った.

\section{実験結果}

切削によって歯䯣腔内の温度が上昇する場合之低下す る場合の典型例を Fig. 1 および 2 に示す，上昇する場 合には雬䯣腔内の温度はほぼ直線的な増加を示し，低下

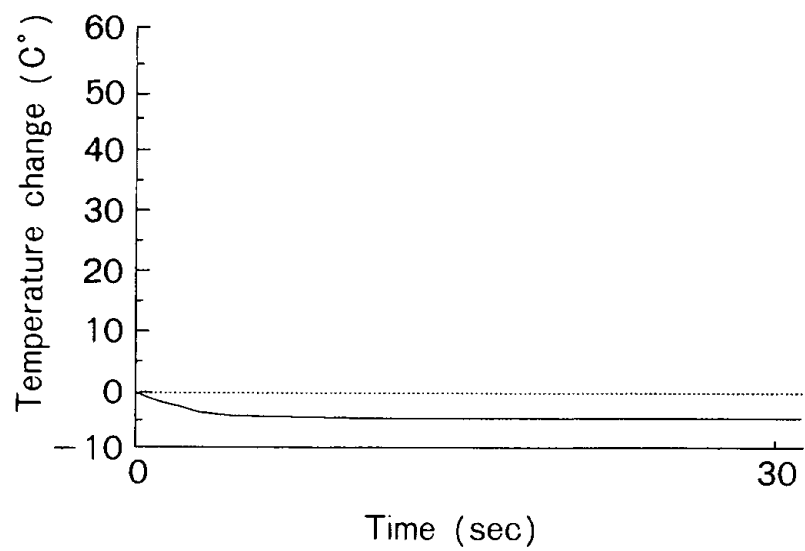

Fig. 2 An example of temperature fall in pulp chamber during cutting. 


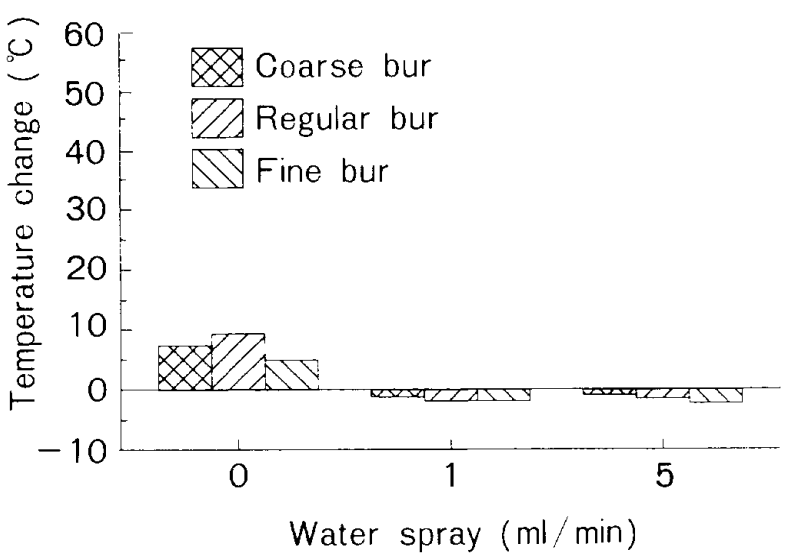

Fig. 3 Temperature change in pulp chamber 30 seconds after the start of cutting (cutting load : $20 \mathrm{~g}$ ).

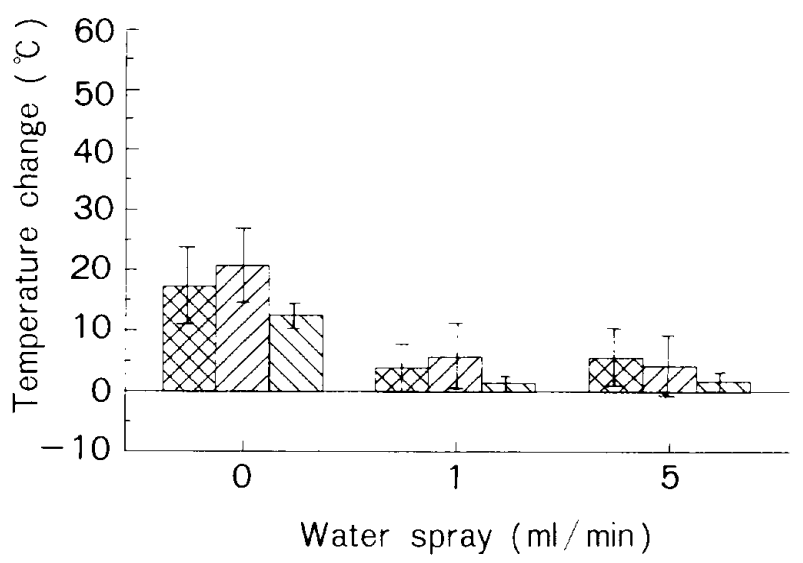

Fig. 4 Temperature change in pulp chamber 30 seconds after the start of cutting (cutting load : $50 \mathrm{~g}$ ).

する場合には，切削開始後数秒でプラトーに達する傾向 を示した．Fig. 3-5 は，切削開始から 30 秒後の㐘䯣 腔内の温度変化量を示している．また，これらの值につ いて三元配置による分散分析を行った結果を Table 1 に示す．切削圧が $20 \mathrm{~g}$ の場合にのみ， $1 \mathrm{ml} / \mathrm{min}$ の注水 をすることによって歯髄空内の温度は低下したが，切削 圧が大きくなると注水しても温度上昇を示すようにな り，切削圧が大きいほじ温度上昇量は著しく大きくなる 傾向にあった（ $\mathrm{p}<0.01 ）$.

粗さの異なるダイヤモンドバーを用いた場合，コース 粒子とレギュラー粒子との間には柬䯣腔内の温度上昇量 に大きな差は認められなかったが，一般にファイン粒子 のバー切削することによって温度上昇は最す小さくなっ た $(\mathrm{p}<0.05)$.

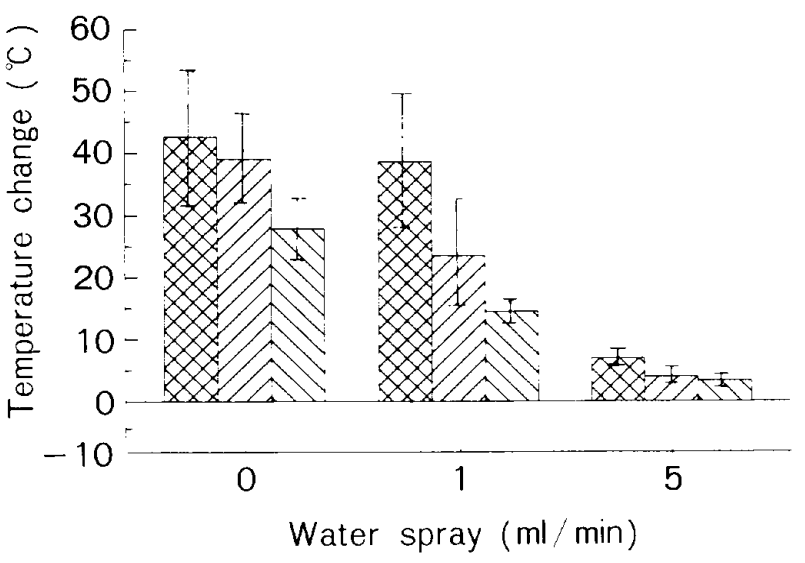

Fig. 5 Temperature change in pulp chamber 30 seconds after the start of cutting (cutting load : $80 \mathrm{~g}$ ).

Table 1 Analysis of varience for the three factors

\begin{tabular}{|c|c|c|c|c|}
\hline Factor & SS & DF & MS & $\mathrm{F}$ \\
\hline A (Load) & $10,220.5$ & 2 & $5,110.2$ & $38.1^{* *}$ \\
\hline B (Grit) & 991.4 & 2 & 495.7 & $3.7^{*}$ \\
\hline C (Spray) & $7,287.8$ & 2 & $3,643,9$ & $27.2^{* *}$ \\
\hline$A \times B$ & 738.3 & 4 & 184.6 & 1.4 \\
\hline $\mathrm{B} \times \mathrm{C}$ & 278.4 & 4 & 69.6 & 0.5 \\
\hline $\mathrm{A} \times \mathrm{C}$ & $2,984.7$ & 4 & 746.2 & $5.6^{* *}$ \\
\hline $\mathrm{A} \times \mathrm{B} \times \mathrm{C}$ & 409.3 & 8 & 51.2 & 0.4 \\
\hline Error & $2,425.1$ & 108 & 22.5 & \\
\hline Total & $25,335.6$ & 134 & & \\
\hline
\end{tabular}

切削時の注水量も㐘䯣腔内の温度上昇に影響を与えた $(\mathrm{p}<0.01)$ が，上くに切削压との間に交互作用が認め られ（p<0.01），切削压が大きい場合之小さい場合之 では注水の効果に差が認められた。切削圧を $20 \mathrm{~g}$ とし た場合には，注水せずに切削すると蒾髄腔内では $10^{\circ} \mathrm{C}$ 前後の温度上昇がみられたが, $1 \mathrm{ml} / \mathrm{min}$ の注水を行う ことによって歯䯣腔内の温度は低下するようになり，注 水量を $5 \mathrm{ml} / \mathrm{min}$ まで増加して屯温度低下值には差は認 められなかった，切削圧が $50 \mathrm{~g}$ の場合，注水せずに切 削する之温度上昇は $20 \mathrm{~g}$ の場合のほぼ 2 倍の值を示し たが，注水することによって温度の上昇量は $5{ }^{\circ} \mathrm{C}$ 前後 にまで減少し，その上昇値は注水量 $1 \mathrm{ml} / \mathrm{min}$ と $5 \mathrm{ml} /$

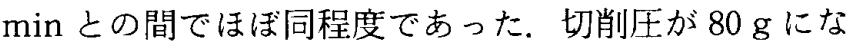
ると, $1 \mathrm{ml} / \mathrm{min}$ の注水ではほとんど効果がなく, $5 \mathrm{ml}$ 
$/ \min$ の注水を行うことによって温度上昇量が抑制され た.

\section{考察}

駒井（1984） ${ }^{111)}$ は，切削荷重 80 および $120 \mathrm{~g}$ で窩洞 形成をイ邓の下䫟 6 前歯に行い，象牙芽細胞に対する傷 害は切削荷重の少ない $80 \mathrm{~g}$ 形成例の方が $120 \mathrm{~g}$ 形成例 より軽微であったと述べている．かっ，歯科医師 14 人 の平均の切削荷重を $84.1 \mathrm{~g}$ と報告している。これらの ことから，切削はできるだけ軽圧で行った方が歯髄腔内 の温度上昇が少なくなるのではないかと考え，切削圧を $80 \mathrm{~g}$ 以下に設定した。切削圧が $80,50,20 \mathrm{~g}$ と小さくな るほど歯䯣染内の温度上昇は有意に低くなり，抑制され た。これは，切削圧が小さいほど切削によって生じる摩 擦熱が減少するためであると考えられる：また，切削面 之歯䯣空までの距離差の影響も考えられるが，切削圧之 切削量が必ずしも正の相関とならないという報告もあ り ${ }^{12)}$, 歯䯣保護の立場加ら発熱量を考慮すれば，切削圧 はできるだけ軽压にした方が好ましいといえる。

Laforgia ら（1991） ${ }^{13)}$ はヒト抜去歯牙を用いた実験 で，ダイヤモンド粒子の塗布の状態の異なった 2 種類の バーを用いて支台歯形成を行ったところ，歯䯣腔内の温 度変化に有意の差を生じたと報告している。

本実験に扔いてはダイヤモンドの粒子が細かくなるほ よ゙歯㖪腔内の温度上昇は小さくなる傾问を示したもの の,コースとレギュラーとの間には有意差が認められな かった. しかし，切削圧が $80 \mathrm{~g}$ の場合，レギュラーよ りコースの方が歯䯣腔内の温度上昇は高い傾向にあり, 切削圧が高くなるほど粒子の粗さの影響が大きくなるの ではないかと考えられる。

Hartnett ら $(1961)^{14)}$ とZach ら (1965) ${ }^{15)}$ は，歯牙 切削時にエアだけの冷却では歯䯣の傷害を防ぐことはで きないと述へ， Laforgia らはエアーウォータースプレイ の冷却効果がェアのみの泠却効果よりも優れていると報 告している.

注水量のほとんどが切削面に当たるような方法で切削 を行った本実験では, 切削時の注水量が $0 \mathrm{ml} / \mathrm{min}, 1$ $\mathrm{ml} / \mathrm{min}, 5 \mathrm{ml} / \mathrm{min}$, と大きくなるほど歯髄腔内の温度 上昇は有意に小さくなった。また，臨床で用いられてい るより屯少ない $5 \mathrm{ml} / \mathrm{min}$ という注水量で, 歯䯣坓内の 温度上昇はある程度抑制されることがわかった。ささ に, 切削压が $20 \mathrm{~g}$ で注水量が $1 \mathrm{ml} / \mathrm{min}$ ならびに $5 \mathrm{ml} /$ min の場合, 歯䯣腔内の温度は $3-4{ }^{\circ} \mathrm{C}$ 低下した。 す なわち，歯䯣腔の温度は $25^{\circ} \mathrm{C}$ から $20^{\circ} \mathrm{C}$ 前後になってお
り，水温近くまで下がったことになる．実験に用いたア ストロンの持つ注水孔は 1 個であるが, 臨床の場では, 冷却能率の向上を目的として, 注水孔が 2 個または 3 個 のハンドピースも使用されている ${ }^{16\rangle}$. 歯髄組織は温度の 低下に対しては上昇よりも強い抵抗性を示すことが報告

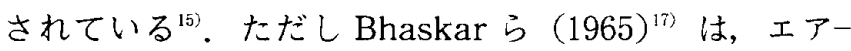
ウォータースプレイによる過冷の歯䯣為害性を指摘して いる．注水量が多いほど冷却効果はよくなるが，過度の 冷却は冷熱刺激を引き起こす可能性むある。そここで，切 削に際しては，冷却水の温度だけではなく注水量の過多 あ考慮する必要があるものと思われる.

\section{結 論}

ヒト下顎切霜抜去歯牙に対して切削圧，ダイヤモンド バーの粒子の粗さならびに注水量を考慮して切削を行 い, 歯䯣腔内の温度変化を測定した結果, 次のような結 論が得られた。

1. 切削圧の大小により, 温度上昇に対する注水の効 果に差が認められた。

2. 切削圧が大きいほど温度上昇量は大きくなり，注 水量が多いほよ゙温度上昇量が小さくなる傾问を示した。

3. 切削圧が $20 \mathrm{~g}$ の場合にのみ, $1 \mathrm{ml} / \mathrm{min}$ の注水に よって歯髄腔内の温度は低下した。

4.ファイン粒子での温度上昇量が最も小さく、コー ス粒子とレギュラー粒子との間に温度上昇量の大きな差 は認められなかった。

\section{引用文献}

1) Swerdlow, H. and Stanley, Jr. H. R. : Reaction of the human dental pulp to cavity preparation. 1. Effect of water spray at 20,000 rpm. J. Amer. Dent. Ass. $56: 317-329,1958$.

2 ) Swerdlow, H. and Stanley, Jr. H. R. : Reaction of the human dental pulp to cavity preparation. 2. at $150,000 \mathrm{rpm}$. with an air-water spray. J. Prosthet. Dent. $9: 121-131,1959$.

3 ) Langeland, K. : Histologic evaluation of pulp reactions to operative procedures. O. S., O. M. \& O. P. 12 (10) : $1235-1248,1959$.

4 ）浅井康宏：支台歯形成之組織被害, クラウン・ブリッジの 臨床 (多和田泰一他編). 医米楽出版, 東京, 1972, 3445.

5 ) 斉藤利夫：高速切削と臨床. 蒾科ジャーナル 9 ：303334, 1979.

6）宮入裕夫, 村松篤良：歯科用エアタービンハンドピースの 性能に関する研究 第 1 報 エアベアリングハンドピース の回転性能に及ぼす供給空気圧力とバーの長さについて. 
歯科理工誌 $20(51): 194-198 ， 1979$

7 ) 宮入裕夫, 永井正洋, 村松篤良: 歯科用エアタービンハン ドピースの性能に関する研究（II）エアタービンハンド ピースの種類とその回転性能. 歯科理工誌 21 (53): 35 $-40,1980$.

8 ）宮入裕夫, 永井正洋, 福田秀昭, 村松篤良：歯科用エア タービンハンドピースの性能に関する研究（III）エアター ビンハンドピースのトルクの湘定. 霜科理工誌 21 (53) : $41-47,1980$.

9）宮入裕夫, 永井正洋, 福田秀昭, 村松篤良：歯科用エア タービンハンドピースの性能に関する研究 (IV) エアター ビンハンドピースの回転性能に関する解析 $\left(\mathrm{N}=\mathrm{N}_{0}-\right.$ $\mathrm{C}_{\mathrm{v}} \mathrm{F}_{\mathrm{v}}{ }^{r}$ )。歯科理工誌 $22(58): 136-142 ， 1981$.

10）松平恭平：歯科用回転工具の種類が高速切削荷重及び工具 回転数に及ぼす影響について．歯科学報 $82: 517-538$, 1982.

11）駒井英基：切削荷重が歯䯣へ及ぼす影響，九州番会誌 38 (1) : 116-131, 1984.

12) Taira, M., Wakasa, K., Yamaki, M. and Matsui, A. :
Effects of the diamond grit sizes of the commercial dental diamond points on the weight-load cutting of bovine enamel and glassceramic typodont teeth. Dent. Mater. J. 9 (2) : 173-180, 1990.

13) Laforgia, P. D., Milano, V., Morea, C. and Desiate, A. : Temperature change in the pulp chamber during complete crown preparation. J. Prosthet. Dent. 65 (1) : $56-61,1991$.

14) Hartnett, J. E. and Smith, W. F. : The production of heat in the dental pulp by use of the air turbine. J. Amer. Dent. Ass. 63:210-214, 1961.

15) Zach, L. and Cohen, G. : Pulp response to externally applied heat. O. S., O. M. \& O. P. 19 (4) : $515-530$, 1965.

16）原 学郎, 土谷広彦, 石川達也, 勝山 茂: 生活菌の切 削. デンタルダイヤモンド $12: 18-32,1981$.

17) Bhaskar, S. N. and Lilly, G. E. : Intrapulpal temperature during cavity preparation. J. Dent. Res. 44 (4) : 644-647, 1965. 